\title{
Pengaruh Fasilitas dan Lokasi Terhadap Kepuasan Pelanggan : Studi Kasus Mahfoed Life Gym
}

\author{
Arta Rutjuhan, Ismunandar \\ Sekolah Tinggi Ilmu Ekonomi Bima \\ Email: artarutjuhan16.stiebima@gmail.com
}

Naskah diterima 24 Maret 2020, Revisi 30 Maret 2020, Terbit 19 April 2020

\begin{abstract}
Abstrak
DOI: doi.org/10.21107/pamator.v13i1.7015

Penelitian ini bertujuan untuk menganalisis pengaruh fasilitas dan lokasi terhadap kepuasan pelanggan Mahfoed Life Gym. Jenis penelitian yang digunakan adalah asosiatif dengan menggunakan pendekatan kuantitatif. Variabel penelitian terdiri dari : fasilitas $\left(\mathrm{X}_{1}\right)$ dan Lokasi $\left(\mathrm{X}_{2}\right)$ sebagai variabel independen, dan Kepuasan Pelanggan sebagai variabel dependen $(\mathrm{Y})$. Seluruh variabel diukur dengan menggunakan skala Likert. Jumlah sampel yang diteliti adalah 60 responden. Pengujian instrumen dengan menggunakan uji validitas dan uji reliabilitas. Alat analisis data yang digunakan adalah regresi linier berganda dengan SPSS. Hasil penelitian menunjukan garis regresi sebagai berikut : $Y=10.6690$ $0,123 \mathrm{X}_{1}+0,334 \mathrm{X}_{2}+\mathrm{e}$. Nilai R (Koefisien Korelasi) yang diperoleh sebesar 0,786 atau $78,6 \%$ dan nilai $\mathrm{R}$ Square (Koefisisen Determinasi) sebesar 0,618 atau 61,8\%. Hasil dalam penelitian ini menunjukan bahwa secara parsial Fasilitas tidak berpengaruh terhadap kepuasan pelanggan sedangkan Lokasi berpengaruh terhadap kepuasan pelanggan. Secara simultan terbukti bahwa Fasilitas dan Lokasi berpengaruh terhadap kepuasan pelanggan Mahfoed Life Gym. Sehingga dapat disarankan kepada pemilik Mahfoed Life Gym untuk melakukan peningkatan dalam hal yang berkaitan dengan lokasi Mahfoed Life Gym.
\end{abstract}

Kata Kunci : kepuasan pelanggan, fasilitas, regresi linear

\begin{abstract}
This study aims to analyze the effect of facilities and location on customer satisfaction Mahfoed Life Gym. The type of research used is associative using a quantitative approach. The research variables consist of: facilities $\left(X_{1}\right)$ and Location $\left(X_{2}\right)$ as independent variables, and Customer Satisfaction as the dependent variable (Y). All variables are measured using a Likert scale. The number of samples studied was 60 respondents. Testing instruments using the validity test and reliability test. The data analysis tool used is multiple linear regression with SPSS. The results showed the regression line as follows: $Y=10.6690-0.123 X_{1}$ $+0.334 X_{2}+e . R$ value (Correlation Coefficient) obtained is 0.786 or $78.6 \%$ and $R$ Square value (Coefficient of Determination) is 0.618 or $61.8 \%$. The results in this study indicate that partially the Facility does not affect customer satisfaction while Location influences customer satisfaction. Simultaneously it is proven that the Facilities and Location affect customer satisfaction Mahfoed Life Gym. So it can be suggested to the owners of Mahfoed Life Gym to make improvements in matters relating to the location of Mahfoed Life Gym.
\end{abstract}

Keywords : customer satifaction, facility, linear regression

\section{PENDAHULUAN}

Lingkungan bisnis dewasa ini berkembang dengan sangat cepat, dan diperlukan adanya sistem manajemen yang efektif dan efisien yang dapat menyesuaikan diri dengan perubahan, baik yang sedang dan telah terjadi dengan cepat, tepat, dan terarah serta biaya yang murah. Dalam perkembangannya, kelangsungan hidup dan pertumbuhan dari suatu bisnis tidak hanya di tentukan dari pengelolaan uang, namun juga ditentukan bagaimana suatu bisnis tersebut sanggup memenuhi apa yang diinginkan konsumen, karena permintaan konsumen beraneka ragam dan berubah ubah.

Lokasi dan fasilitas juga menjadi peran yang sangat penting bagi perusahaan untuk menarik para konsumen. Lokasi merupakan salah satu bagian mendasar bagi konsumen dalam pemutusan pembelian, apabila lokasi perusahaan mudah dijangkau, dan mudah diakses oleh transportasi maka perusahaan tersebut mempunyai nilai tambah tersendiri. Begitu juga dengan fasilitas, fasilitas adalah sarana yang sifatnya mempermudah konsumen untuk melakukan suatu aktivitas. 
Konsumen akan mempertimbangkan banyak faktor untuk memilih sebuah produk, lokasi dan fasilitas juga termasuk pertimbangan konsumen dalam keputusan pembelian. Pada tingkat harga yang hampir sama, semakin lengkap fasilitas yang disediakan perusahaan, maka akan semakin puas pelanggan dan ia akan terus memilih perusahaan tersebut sebagi pilihan prioritas berdasarkan persepsi yang ia peroleh terhadap fasilitas yang tersedia.

Saat ini persaingan dunia bisnis kini sangat ketat seiring dengan semakin meningkatnya permintaan masyarakat terhadap produk dan jasa untuk memenuhi segala kebutuhannya. Demi menjaga kelangsungan usaha di tengah-tengah persaingan bisnis yang sangat kompetitif, suatu perusahaan harus memberikan kepuasan kepada konsumennya, menurut Prasetio (2012). Fasilitas merupakan penyediaan perlengkapan-perlengkapan fisik untuk memberikan kemudahan kepada tamu dalam melaksanakan aktivitasaktivitasnya atau kegiatan-kegiatannya, menurut Sulastiyono (2011).

Mahfoed life gym merupakan tempat kebugaran tubuh yang ada di Kota Bima yang menawarkan kegiatan olahraga di dalam ruangan dari yang menggunakan alat seperti : dumble, barbel, tredmill dll, sampai yang tidak menggunakan alat seperti: stretching, push up, squad, tricep dip, crunch dan lain-lain. Observasi yang di lakukan oleh peneliti menemukan banyak keluhan mengenai fasilitas yang ada di mahfoed life gym seperti kurangnya dumble, barbel dan tredmill serta lokasi atau tempat parkir kendaraan yang kurang memadai terutama banyaknya pelanggan yang datang pada hari sabtu dan hari minggu

\section{METODOLOGI}

Jenis penelitian yang digunakan dalam penelitian ini adalah penelitian asosiatif, karena penelitian ini mencari adakah pengaruh atau hubungan antara dua variabel atau lebih yaitu Pengaruh Fasilitasi Dan Lokasi Terhadap Keputusan Pembelian Konsumen Pada kepuasan pelanggan di mahfoed life gym. Dalam penelitian ini yang menjadi populasi adalah para member pada mahfoed life gym. Oleh karena itu populasi ini merupakan populasi terbatas karena dapat diketahui secara pasti jumlah sebenarnya dari pelanggan yang telah terdaftar sebagai member di mahfoed life gym. Penentuan sampel dalam penelitian ini dilakukan dengan metode purpose sampling merupakan bagian dari teknik sampel yang pengambilannya sampel dengan cara menetapkan ciri-ciri khusus yang sesuai dengan tujuan penelitian sehingga diharapkan dapatmenjawab permasalahan penilitian. Karena jumlah populasinya dapat diketahui secara pasti maka untuk menentukan besarnya sampel digunakan rumus Slovin Population.

Dimana:

$$
N=\frac{N}{1+N e^{2}}
$$

$$
\begin{array}{ll}
\mathrm{n} & =\text { jumlah sampel } \\
\mathrm{N} & =\text { jumlah seluruh populasi } \\
\mathrm{e} & =\text { toleransi error }
\end{array}
$$

Maka jumlah sampel yang didapat adalah :

$$
N=\frac{150}{1+0,05^{2}}=60
$$

Instrumen penelitian menggunakan kuesioner/angket yang berisi serangkaian pernyataan yang di berikan kepada responden guna memperoleh data yang dibutuhkan dengan menggunakan Skala Likert. Teknik pengumpulan data yang digunakan yaitu : (a) Observasi; Angket/kuesioner; (c) Studi Pustaka. Lokasi penelitian ini dilakukan pada Mahfoed Life Gym. Dimulai pada bulan Desember 2019 sampai dengan Januari 2020.

Jenis data yang digunakan adalah Data Kuantitatif. Adapun sumber data yang digunakan dalam penelitian ini adalah data primer, dilakukan uji validitas data, reliabilitas data dan uji asumsi klasik. Teknik analisis yang digunakan adalah Analisis regresi linier berganda, dengan persamaan :

$$
\mathrm{Y}=\beta_{0}+\mathrm{b}_{1} \mathrm{X}_{1}+\mathrm{b}_{2} \mathrm{X}_{2}+\varepsilon
$$

Dimana $Y$ merupakan kepuasan pelanggan, $\beta_{0}$ adalah konstanta, $b_{1}, b_{2}$ adalah koefesien regresi, $\mathrm{X}_{1}$ adalah fasilitas, $\mathrm{X}_{2}$ adalah lokasi dan $\varepsilon$ adalah error term. Selain itu dilakukan perhitungan koefisien korelasi $(r)$, koefisien determinasi $\left(R^{2}\right)$, uji t dan uji $F$.

\section{HASIL PEMBAHASAN}

Dari hasil perhitungan dapat dilihat bahwa seluruh instrumen dalam penelitian ini memiliki nilai validitas $>0.250$. Sehingga instrumen dalam penelitian ini dikatakan valid dan layak digunakan dalam penelitian. 
Dari perhitungan ini juga diperoleh bahwa seluruh instrumen dalam penelitian ini memiliki nilai alpha $>0.60$, oleh karena itu instrumen memenuhi strandar reliabilitas dan dapat digunakan dalam penelitian ini.

Perhitungan uji asumsi klasik, untuk uji normalitas data diperoleh nilai signifikan sebesar 0,502 > dari nilai alpha 0,05, sehingga dapat simpulkan bahwa data dalam penelitian ini berdistribusi normal. Untuk uji heterokeastisitas, diperoleh bahwa tidak terjadi gejala heterokeastisitas dalam penelitian ini. Uji Multikolinearitas, dapat dilihat bahwa nilai VIF masing-masing variabel independen 1,154 < 10,00 sehingga dapat disimpulkan bahwa tidak terjadi gejala multikolinieritas dalam penelitian ini. Uji autokorelasi, dengan jumlah sampel sebanyak 60 , diperoleh nilai $\mathrm{dU}=1,6518$ dan nilai $d=1,835$. Nilai $d_{\text {hitung }}$ sebesar, dan nilai $4-\mathrm{dU}=2,3482$. maka dapat di simpulkan dU $1,6518<$ d 1,835 < 4-dU 2,3482 , yang artinya tidak terjadi autokorelasi dalam penelitian ini.

\section{Uii Regresi Linear Berganda}

Tabel 1. Hasil Uji Regresi Linear Berganda

\section{Coefficients $^{a}$}

\begin{tabular}{|l|l|r|r|r|}
\hline \multirow{2}{*}{} & \multicolumn{2}{|c|}{$\begin{array}{c}\text { Unstandarized } \\
\text { Coefficients }\end{array}$} & $\begin{array}{c}\text { Standardized } \\
\text { Coefficients }\end{array}$ \\
\cline { 3 - 5 } \multicolumn{2}{c|}{ Model } & \multicolumn{1}{c|}{$\mathrm{B}$} & Std. Error & \multicolumn{1}{c|}{ Beta } \\
\hline \multirow{3}{*}{1} & (Constant) & 10,086 & 2.661 & \\
\cline { 2 - 5 } & Fasilitas & -.123 & .063 & -.173 \\
\cline { 2 - 5 } & Lokasi & .334 & .035 & .832 \\
\hline
\end{tabular}

a.Dependent Variable : Kepuasan Pelanggan

Dari hasil analisis regresi linier berganda di atas, dapat diperoleh persamaan sebagai berikut: $Y=10,669-0,123 X_{1}+0,334 X_{2}+$ e. Nilai konstanta positif sebesar 10,669, hal ini menunjukkan apabila Nilai konstan (Y) sebesar 10,669 artinya jika variabel fasilitas $\left(X_{1}\right)$ dan lokasi $\left(X_{2}\right)$ bernilai nol $(0)$, maka kepuasan pelanggan pada mahfoed life gym (Y) akan berada pada angka 10,669. Artinya keofisien regresi $X_{1}$ (fasilitas) dari perhitungan liner sederhana di dapatkan nilai coefficients $(b 1)=-0,123$. Hal ini berarti bahwa jika tidak terjadi kenaikan fasilitas pada Mahfoed life gym sebesar 1\% maka kepuasan pelanggan pada Mahfoed life gym juga tidak akan mengalami kenaikan sebesar variabel pengalinya yaitu $-0,123$.
Dengan asumsi variabel independen yang lain tidak dianggap konstan. Keofisien regresi $\mathrm{X}_{2}$ (lokasi) dari perhitungan liner sederhana di dapatkan nilai coefficients (b1) $=0,334$. Hal ini berarti jika terjadi kenaikan presensi sebesar $1 \%$ maka maka kepuasan pelanggan pada Mahfoed life gym juga akan mengalami kenaikan sebesar variabel pengalinya yaitu 0,334 . Dengan asumsi variabel independen yang lain dianggap konstan (sama).

Tabel 2. Koefisien Determinasi

Model Summary ${ }^{b}$

\begin{tabular}{|l|c|c|}
\hline Model & $\mathrm{R}$ & R Square \\
\hline 1 & $.786^{\mathrm{a}}$ & .618 \\
\hline
\end{tabular}

Tabel di atas menunjukkan bahwa $61,8 \%$ variabel dependent (kepuasan pelanggan) dapat dijelaskan oleh variabel independent (fasilitas dan lokasi), sedangkan sisanya $38,2 \%$ dipengaruhi oleh variabel lain yang tidak diteliti dalam penelitian ini. Hasil dari uji koefisien determinasi tersebut memberikan makna bahwa masih terdapat variabel independent lain yang mempengaruhi terhadap kepuasan pelanggan. Untuk itu perlu pengembangan penelitian lebih lanjut terkait dengan topik ini.

Tabel 3. Analisis Korelasi Berganda Model Summary ${ }^{\mathrm{b}}$

\begin{tabular}{|l|r|r|}
\hline Model & F change & Sig.F change \\
\hline 1 & 46,081 & .000 \\
\hline
\end{tabular}

Uji korelasi berganda bertujuan untuk mengatahui tingkat keeratan hubungan (sumultan) antara dua atau lebih variabel bebas (X) terhadap variabel terikat (Y).pengambilan keputusannya jika nilai sig. $F_{\text {change }}<0,05$ maka data tersebut berkorelasi (berhubungan) sebaliknya jika nilai sig $F_{\text {change }}>0,05$ maka data tersebut tidak berkorelasi (tidak berhubungan). Pada tabel di atas didapatkan nilai sig. $F_{\text {change }}$ sebesar $0,000<0,05$, artinya keseluruhan data yang peniliti sajikan berkorelasi atau berhubungan dengan demikian penilitian dihentikan. 
Uii Parsial (Uji-t)

Tabel 4. Hasil Uji Parsial (Uji-t)

Coefficients $^{a}$

\begin{tabular}{|l|l|r|r|}
\hline \multicolumn{2}{|l|}{ Model } & \multicolumn{1}{c|}{$\mathrm{t}$} & \multicolumn{1}{c|}{ Sig. } \\
\hline 1 & (Constant) & 4,086 & .000 \\
\cline { 2 - 4 } & Fasilitas & $-.1,967$ & .054 \\
\cline { 2 - 4 } & Lokasi & 9,466 & .000 \\
\hline
\end{tabular}

Dari tabel diatas diperoleh t hitung untuk variable fasilitas sebesar $-1,967$ dan. Diperoleh nilai $t_{\text {tabel }}(\mathrm{df}=\mathrm{n}-2(60-2=58)=$ 1,671 dengan tingkat kesalahan $5 \%$. Dalam penelitian ini variabel fasilitas memiliki $t_{\text {hitung }}$ $1,967<t_{\text {tabel }} 1,67155$ dan nilai signifikansi $0,54>0,05$ sehingga $\mathrm{H} 1$ ditolak dan $\mathrm{H} 0$ yang menyatakan bahwa tidak terdapat pengaruh fasilitas terhadap kepuasan pelanggan pada mahfoed life gym diterima.

Untuk variabel lokasi, diperoleh nilai thitung sebesar 9,466 $>t_{\text {tabel }} 1,671$ dengan nilai signifikansi $0,00<0,05$ sehingga dapat disimpulkan bahwa $\mathrm{H}_{0}$ ditolak dan $\mathrm{H}_{2}$ yang menyatakan terdapat pengaruh lokasi terhadap kepuasan pelanggan pada mahfoed life gym dapat diterima.

\section{Uji Simultan (Uji-F)}

Tabel 5. Hasil Uji F

\section{Coefficients $^{a}$}

\begin{tabular}{|l|l|l|r|}
\hline \multicolumn{2}{|l|}{ Model } & \multicolumn{1}{|c|}{$\mathrm{F}$} & \multicolumn{1}{c|}{ Sig. } \\
\hline \multirow{3}{*}{1} & Regression & 46,081 & .000 \\
\cline { 2 - 4 } & Residual & & \\
\cline { 2 - 4 } & Total & & \\
\hline
\end{tabular}

Dari tabel ANOVA diperoleh $F_{\text {hitung }}$ sebesar 46,081. Untuk menentukan $F_{\text {tabel }}$ digunakan lampiran statistika $F_{\text {tabel }}$ dengan menggunakan $\alpha=5 \%$. Nilai $\mathrm{df}_{1}$ (jumlah variabel -1$)$ atau $3-1=2$ dan $\mathrm{df}_{2}(\mathrm{n}-\mathrm{k}-1)$ atau $60-2-1=57$. Maka diperoleh $F_{\text {tabel }}$ sebesar 3,16. Dari hasil pengujian diatas dapat diketahui bahwa nilai $F_{\text {hitung }} 46,081>F$ tabel 3,16 dengan nilai signifikansi sebesar $0,000<0,05$, sehingga dapat disimpulkan bahwa $\mathrm{H}_{0}$ ditolak dan $\mathrm{H}_{3}$ yang menyatakan bahwa fasilitas dan lokasi berpengaruh terhadap kepuasan pelanggan pada mahfoed life gym dapat diterima.

\section{KESIMPULAN}

Berdasarkan hasil penelitian dapat disimpulkan bahwa, (1) Tidak ada pengaruh antara fasilitas terhadap kepuasan pelanggan pada Mahfoed Life Gym; (2) Ada pengaruh antara variabel lokasi terhadap kepuasan pelanggan Mahfoed Life Gym; (3) Secara simultan terdapat pengaruh antara fasilitas dan lokasi terhadap terhadap kepusan pelanggan Mahfoed Life Gym.

Dari hasil penelitian ini peneliti menyarankan agar pemilik Mahfoed Life Gym dapat melakukan pengembangan yang berkaitan dengan lokasi dan pelayanan. Walaupun variable fasilitas tidak berpengaruh namun disarankan pemilik agar menyesuaikan dan menstandarisasi fasilitas yang berada di Mahfoed Life Gym sesuai dengan kebutuhan pelanggan.

\section{DAFTAR PUSTAKA}

Ardiawan, P. 2018. Pengaruh Kualitas Pelayanan, Fasilitas dan Lokasi Terhadap Kepuasan Konsumen pada Lapangan Futsal Mareno 2 Ngunut Tulungagung. Simki Economic. Vol 2 No 1.

Gama, A, W, S. Rustiarini, N, W. \& Anggraini, N, P, N. 2016. Pengaruh Lokasi, Fasilitas dan Pelayanan Terhadap Keputusan Pembelian (Studi Pada Pasar Seni Guwang Suka Wati). Jurnal Ekonmi \& Pariwisata Vol. 11 No. 1

Dewandi. Kasih, Y. \& Idham, C. 2014. Pengaruh Kualitas Pelayanan, Fasilitas, dan Harga Terhadap Kepuasan Konsumen pada Hotel Emilia Palembang. STIE MDP.

Sulistiyana, R.T. Hamid, D. \& Azizah, F, A. 2015. Pengaruh Fasilitas Wisata dan Harga Terhadap Kepuasan Konsumen (Studi Kasus Pada Museum Satwa). Jurnal Administrasi Bisnis Vol 25, No 2.

Mardiyanti, Y. \& Murwatiningsih 2015. Pengaruh Fasilitas dan Promosi Terhadap Kepuasan Pengunjung 
Melalui Keputusan Berkunjung Sebagai Variable Intervening pada Objek Wisata Kota Semarang. Management Analysis Journal. Vol 4 No 1.

Purnomo, E. \& Makmur, Y.A. 2017 Pengaruh Harga, Kualitas Produk Dan Lokasi Dalam Pembelian Beras Lokal (Studi Kasus Desa Rambah Utama. EJournal Mahasiswa Prodi Manajemen. Vol 4 No 1.
Prasetio, A. 2012. Pengaruh Kualitas Pelayanan dan Harga Terhadap Kepuasan Pelanggan. Management Analysis Journal 1. Hal. 1-6.

Sulastiyono, A. 2011. Manajemen Penyelenggaraan Hotel. Seri Manajemen Usaha Jasa Sarana Pariwisata dan Akomodasi. Alfabeta. Bandung. 